\title{
MASKED PERFORATION OF A GASTRIC ULCER IN A CASE OF TABES DORSALIS*
}

\author{
BY \\ J. OLIVER DOYLE and DOUGLAS J. CAMPBELL \\ Department of Venereology, Royal Hospital, Sheffield
}

Silent perforation of a peptic ulcer in a tabetic has on rare occasions been recorded. The following case recently seen in the Department of Venereology, Doncaster Royal Infirmary, is considered to be of sufficient interest to merit publication.

\section{Case Report}

An obese male aged 68 years attended the surgical out-patients' department in April, 1951, with leukoplakia of the left cheek. His blood Wassermann reaction was positive $1: 80$, and the Kahn reaction strongly positive. He had been treated for hypertensive heart failure in 1948, osteo-arthritis of the spine in 1950, and cholecystitis in March, 1951. $X$ ray of the gall-bladder in March, 1951, was negative. He received sixteen megaunits procaine penicillin " $G$ " in oil, $8.5 \mathrm{~g}$. neoarsphenamine and $4 \mathrm{~g}$. bismuth.

On May 10,1952, the patient had what appeared to be a brisk haemoptysis. Radiographic examination of the chest on May 12, 1952, revealed no significant pulmonary abnormality. On September 22, 1952, he complained of severe "shooting" pains in the legs, between the shoulder blades, round the sides of the chest, the epigastrium, and the right hypochondrium. There was neither vomiting, loss of weight, nor loss of appetite. When referred to us at this stage we found he had typical signs of tabes dorsalis, which was confirmed by examination of the cerebrospinal fluid. There was slight tenderness on deep pressure in the right hypochondrium. A barium meal examination on October 8, 1952, showed no ulcer crater in the stomach or duodenum. Further penicillin, arsenic, and bismuth were administered.

On November 27, 1952, the patient was admitted to hospital as a surgical emergency with acute retention of urine of 2 days' duration and generalized abdominal pain of one day's duration. On examination he was breathless, with pulse 100 , temperature $97^{\circ} \mathrm{F}$., and respiration 22. Rales and rhonchi were scattered over the chest. The bladder was distended to the umbilicus. There was guarding and tenderness in the right hypochondrium. The prostate was small and hard.

\footnotetext{
* Received for publication March 18, 1953.
}

About $20 \mathrm{ml}$. bloodstained urine was withdrawn by metal catheter. A tentative diagnosis of carcinoma of the prostate was made. The patient died the following day.

Post-mortem examination on November 28, 1952, showed gross distension of the abdomen. A generalized coliform peritonitis and a perforated chronic gastric ulcer $1 \mathrm{~cm}$. in diameter situated in the juxta-pyloric region were present. The ulcer was surrounded by a moderate degree of induration but there was no evidence of malignancy. There was a marked degree of pyloric stenosis; the stomach was grossly dilated, and the muscle wall considerably hypertrophied. Both kidneys showed marked toxic changes. The prostate was relatively normal in size and the bladder mucosa showed some injection. There was a gross degree of cardiac hypertrophy with dilatation of the left ventricle. The ascending aorta was considerably dilated and the aortic valve cusps were thickened, puckered, and scarred. There was naked-eye evidence of a syphilitic mesaortitis of the ascending and thoracic aorta. There was a gross degree of chronic hypertrophic emphysema and chronic tracheobronchitis. Unfortunately the central nervous system was not examined.

\section{Discussion}

It is known that tabes dorsalis may on rare occasions account for loss of painful visceral sensations and so mask abdominal catastrophies.

Hanser (1919) has shown that in some tabetic patients the viscera are insensitive. He published a case of silent perforation of an ulcer of the small intestine in a tabetic; a peritonitis of several days duration was found at autopsy, the patient having had no abdominal signs or symptoms.

Roux (1900) discovered many degenerate fibres in the splanchnic bundle in tabetics. 
Hunt and Lisa are quoted by Stokes and others (1944) as stating that an associated gastric or duodenal ulcer and tabes dorsalis is uncommon. They concluded that such association does not represent, as might be thought probable, a trophic type of ulcerative change in the gastric or duodenal mucosa associated with the neuro-syphilis.

Conner (1910) recorded a case of silent perforation of an appendix abscess in a tabetic.

Sternberg (1929) described cases of painless pneumonia and pleurisy in tabetics.

Grimble and Csonka (1952) described the case of a tabetic of 59, who seemingly died of heart failure, although at necropsy they found a large chronic gastric ulcer which had apparently perforated some 3 days previously. The abdomen had been distended during his last days, but he had no tenderness or pain and had been able to eat solid food an hour before he died. The pathological findings in the central nervous system were those of moderately severe tabes dorsalis associated with meningovascular syphilis. There was no evidence of paresis, and they were of the opinion that the true visceral pain pathway from the stomach was interrupted by the syphilitic process, thus explaining the painless course over several years of a large gastric ulcer. They considered that both autonomic and somatic channels must be affected bilaterally for a painless abdominal catastrophe to occur.

Our patient complained of severe pain in the right hypochondrium accompanied by severe shooting pains in the legs, arms, chest, and epigastrium. The negative barium series and $x$ ray of the gall-bladder suggested that the pain in the right hypochondrium was probably of the classical "shooting" type.

\section{Summary}

A case of masked perforation of a gastric ulcer in a tabetic is presented, suggesting that in tabes dorsalis visceral pain may be diminished or absent. The difficulties in diagnosis are stressed and the relevant literature briefly discussed.

\section{REFERENCES}

Conner, L. A. (1910). J. Amer. med. Ass., 55, 1427.

Grimble, A. S., and Csonka, G. W. (1952). British Journal of Venereal Diseases, 28, 61.

Hanser, A. (1919). Dtsch. med. Wschr., 45, 129.

Hunt and Lisa. Quoted by Stokes and others (1944).

Lancet (1952) 2, 673, Annotation.

Roux, J. C. (1900). "Lés lesions du système grand sympathique dans le tabés et leur rapport avec les troubles de la sensibilité viscerale," Thèse de Paris, No. 388.

Sternberg, M. (1929). Dtsch. Z. Nervenheilk, 107, 97.

Stokes, J. H., Beerman, H., and Ingraham, N. R. (1944). " "Modern Clinical Syphilology ", 3rd ed. Saunders, Philadelphia. 